\title{
What is medicine?: towards a philosophical approach
}

\author{
David Greaves Social Paediatric and Obstetric Research Unit, Glasgow
}

\section{Summary}

The failure of Western medicine to deal with many of the problems it is currently facing has led to an awareness of the need for a fundamental reappraisal. The way in which medical concepts derived from the nineteenth century have brought technical medical advances in this century and the alliances that medicine has made with statistics and more recently the social sciences, have prevented a questioning of medicine's underlying assumptions. Thus, despite a number of critical initiatives from both within and outside medicine, there has been no coherent development to seriously confront the question 'what is medicine?'. It is suggested that the basis for such a development depends on the return to a philosophical questioning of our conceptual understanding of disease, a subject which has largely been ignored during the past hundred years.

\section{Introduction}

A number of developments, sometimes referred to collectively as the 'crisis' of Western medicine, have brought about a gradual realisation of the need for a serious reappraisal of the entire medical enterprise.* These may be summarised as follows:

I) The change in disease patterns away from acute treatable illness episodes to chronic intractable conditions, which are only marginally affected by the traditional techniques of medical management already established or being developed by scientific medicine.

2) The failure of increasing levels of expenditure on health care to meet the demands which have been placed on health services which have partly arisen from these new chronic disease 'epidemics'.

3) A realisation that need for health care is not readily definable as a fixed quantity and that dealing with immediate problems may lead to many more being uncovered.

* This idea of there being a crisis in medicine, in response to which a fundamentally new approach is required, compares with Kuhn's theory of the way in which new paradigms arise within scientific disciplines (Kuhn, T S (1970) The Structure of Scientific Revolutions, 2nd Ed.)
4) The preceding points have further led to an awareness that the definition of those areas of life which are legitimately medical and should therefore be controlled by health professionals and are appropriately dealt with by their methods of working, is itself problematic.

5) An increasing awareness of the impersonality of many aspects of Western technical medicine and the need to re-emphasise a personalised approach to the medical enterprise.

6) An increased desire on the part of society to be informed about and take part in decision-making in all areas of life. This has inevitably brought conflict with the professions, including the medical profession, who have traditionally seen their discipline as containing a body of knowledge which is their exclusive preserve.

7) An intellectual awareness in Western society that its technology is failing to deal with many of the world's most serious problems, e.g. resource depletion, population. Though this may as yet have had little effect on day-to-day life, it has diminished Western society's confidence in all technological solutions and this awareness has been applied to medicine.

\section{Why medicine has not developed a philosophical approach}

These developments have meant that it can no longer be taken for granted that what medicine is and what health care professionals should be doing is self-apparent. They may be formulated into a single overarching question, 'What is medicine?' The further problem which then arises is why this question has not been identified as an important contemporary issue.

In attempting to explore this it may be helpful to look at an example of one of the many disciplines which, during the present century, has conceived the need to ask, 'What is it ?', in considering its own subject. Carr ${ }^{1}$ has written eloquently on this topic in relation to history and so has provided useful insights for a comparison with medicine:

The liberal nineteenth century view of history had a close affinity with the economic doctrine of laissez-faire, also the product of a serene and self-confident outlook on the world. Let everyone get on with his particular job, and the hidden hand 
would take care of the universal harmony. The facts of history were themselves a demonstration of the supreme fact of a beneficent and apparently infinite progress towards higher things. This was the age of innocence, and historians walked in the Garden of Eden, without a scrap of philosophy to cover them, naked and unashamed before the God of history. Since then, we have known Sin and experienced a Fall; and those historians who today pretend to dispense with a philosophy of history are merely trying, vainly and self-consciously, like members of a nudist colony, to recreate the Garden of Eden in their garden suburb. Today the awkward question can no longer be evaded.

The two points from this passage which have direct relevance for medicine are, first, that historians previously believed that the meaning of their subject was implicit and self-evident and, second, that this attitude flowered in the nineteenth century, which for the intellectuals of Europe, was a comfortable period exuding confidence and optimism in line with the prevailing political and economic ethos. Both have parallels in medicine during the same period. Why, though, should contemporary twentieth century medicine have failed to develop a coherent philosophy of medicine (meaning, as Carr does, a self-questioning attitude) when history along with the majority of other subjects, and notably for medicine the biological sciences, have developed a philosophy of their subjects ?

To answer this, it is necessary to examine the understanding of medicine held in the late nineteenth century. At this time the concept of disease as an entity had become reified by its expression in the unifactorial disease model, which was both nurtured and sustained by the technological confidence of the period and its belief in its own ability to solve problems. The issue which distinguishes medicine from other subjects, though, is the way in which this concept and model have affected the practice of medicine and then been further developed in the present century. First, the technological promise for new methods of disease management, envisaged by the original architects of the unifactorial model was not significantly realised for more than half a century and in relation to the infectious diseases around which it had been created, the most penetrating 'breakthroughs', both in the curative and preventive fields, came in the period from the 1930s to the 1950s. These new triumphs for medical technology were also by implication, triumphs for the old disease concept and model. Additionally, they elevated the already high status of hospital medicine with which technology had been traditionally associated, and this had the effect of furthering the hospital orientation of medical teaching with its emphasis on the acute specialties, so inhibiting any academic pretensions of general practice.
For their part society, and not least politician $\frac{\mathbb{Q}}{8}$ greeted these medical discoveries with an almost euphoric belief in the potential of medicine to solve all ills and this conveniently matched the political mood of the times for increased stat welfare. In Britain, this reached its height during the post-war Labour administration which includef as possibly its most far-reaching reform, the settin up of the National Health Service.

Other developments were also to insulate medicine from questioning itself. The first of these was the emergence of the multifactorial disease model. It $\overrightarrow{9}$ creation depended on the development of scientific techniques in the twentieth century which had nos previously been associated with medicine. These were originally statistical and derived from Fisher's seminal work, first published in 1925. They botin allowed the conception of the new medical modpl and later continued to support and sustain it, as thef do today. Once the model was established other 'non-medical' techniques were also applied to medical problems in such a way as to support the model. These were the cost/benefits approach decision-making derived from economics, first applied at the individual patient level and increasingly now at community level and the development of behavioural/medical models certain groups of social scientists. In the last tuto decades all these techniques have been boosted an further legitimated by the development of computis technology.

Despite this burgeoning growth of new technolog which has become allied with medicine, it has largely been medicine's own concepts and unders standing which have determined how the new techniques have been employed in practice. Medicine, then, has called the tune, sometimes obtaining the willing co-operation of members the parent disciplines, whilst at others failing comprehend or ignoring those who refuse swallow medicine's assumptions unquestioningl The paradox in all this has been the ability of medicine and the medical profession to divoros itself from the label 'scientific' and to continue insist that medicine is a practical subject in the nature of a craft (and this is one sense in whi@ medicine is frequently referred to by doctors as art, rather than a science) which has enabled it resist being seriously challenged by the question 'What is medicine?'.

\section{New initiatives}

Nevertheless, it may reasonably be argued that number of initiatives have already been made response to the question 'What is medicine?'. It $\overline{\$}$ not the present purpose to explore these in detail but they may be seen to have come from both withy medicine and from outside it and be represented os shown in Table $\mathrm{I}$ : 


\section{Within Medicine}

I) General practice, paediatrics, geriatrics - these have in common a whole view of man, as opposed to those specialties which are defined by bodily systems.

2) Community or social medicine (previously public health) these emphasise the relevance of the group or population rather than the individual.

3) Psychiatry - which holds a marginal position in in the main medical enterprise, dealing as it does with the mind rather than the body.

\section{Outside Medicine}

I) Service providers - from professional groups whose disciplines overlap with medicine, but who view their service role from a different perspective.

2) Academics - mainly from the social sciences notably sociology, anthropology, social history (also a recent initiative in North America to engage philosophers in medical issues).

3) Political pressure groups and consumer groups e.g. Women's groups concerning abortion.

4) Individual 'entrepreneurs' e.g. Dubos, Illich.
The point to be made is that although these different groups have raised many questions and conducted extensive investigations into topics related to the present theme, they have not seen the need for a unified philosophical approach with an interdisciplinary make-up and so have not become welded together to produce a coherent response. Increasing specialisation and hence fragmentation both within medicine and the other disciplines involved is itself a serious barrier to such an initiative.

\section{The basis for a philosophical approach}

There is a more fundamental question, though, which will continue to inhibit the development of such a united challenge to the medical enterprise, until it has been recognised and seriously confronted. In $1954 \mathrm{King}^{3}$ described it as follows:

Does a disease, whatever it is, have real existence, somehow, in its own right, in the same way as the continent of Australia ? Such real existence would be independent of its discovery by explorer or investigator. A disease exists whether we know it or not. The contrasting point of view would hold, that a disease is created by the inquiring intellect, carved out by the very process of classification, in the same way that a statue is carved out of a block of marble by the chisel strokes of the sculptor.

The dangers in the unquestioning acceptance of the first understanding, which holds for both the unifactorial and multifactorial disease models have occasionally been recognised during the last hundred years, e.g. Virchow, ${ }^{4}$ Cohen. ${ }^{5}$ The mainstream of medicine and its associated disciplines, however, have ignored these isolated warnings. In consequence, the challenges referred to have remained fragmented and the techniques described which derive from statistics and the behavioural and social sciences (the most recent and politically powerful coming from economics) continue increasingly to provide medicine with a scientific legitimacy whilst protecting its underlying assumptions. The irony of this situation is that the groups which are providing the challenge to medicine have frequently come from the same disciplines from which the techniques have been developed for medicine to protect itself. Therefore, although the theory of medicine (with its recognised modes of teaching, research and practice) and the practical issues which medicine faces may be repeatedly demonstrated to be incongruent, without recognition of the deep-seated philosophical dysjunctions, the challenges described are unlikely ultimately to produce other than marginal adjustments in the main medical enterprise.

\section{Conclusion}

In order to change this situation a conscious effort will be required to envisage medicine freed of the philosophical conception of diseases as things and the most obvious way of attempting this would be to explore the implications of returning to the alternative philosophical approach which makes the sick individual the focus, so that his illness is inseparable from him and diseases alone are no longer recognisable.

To attempt such a task would require the involvement of all those disciplines which are currently challenging medicine, together with a new commitment to their developing an interdisciplinary approach. The philosophical foundation of such an initiative might appear divorced from the everyday practice of medicine, and therefore impotent in providing practical solutions for change. To avoid this, the force of such an enterprise would need to combine with this theoretical perspective, empirical approaches to particular medical situations. Neither should it be thought that such a radical philosophical change would be likely to bring about any immediate parallel changes in either the structure of services or the way in which health professionals carry out their work. Rather, it would give a more pointed focus to changes which are already occurring and would hopefully modify these into producing more lasting solutions to the 'crisis' of Western medicine. 


\section{References}

${ }^{1}$ Carr, E H (196r). What is History ? London, MacMillan. 'Fisher, R A (1925). Statistical Methods for Research Workers. Bdinburgh, Oliver and Boyd.

'King, I S (1954). Philosophy of Science. 21, 193-203.
"Virchow, R (1895). Hundert Fahre Allgemeiner Pathologi English Translation - Rather, L J (1958) Disease, Life and Man: Selected Essays by Rudolf Virchow.

'Cohen, $\mathrm{H}$ (1943). The Nature, Method and Purpose of Diagnosis. Cambridge, Cambridge University Press: 